\title{
Comunicação
}

[Communication]

\section{Fungos anaeróbios do rúmen de bovinos e caprinos de corte criados em pastagens tropicais}

[Ruminal anaerobic fungi of beef cattle and beef goats raised on tropical pastures]

\author{
F.O. Abrão, S.M.P. Barreto, L.C. Geraseev, E.R. Duarte
}

Instituto de Ciências Agrárias - Universidade Federal de Minas Gerais

Av. Universitária, 1000

39400-006 - Montes Claros, MG

Considerando as propriedades enzimáticas, fisiológicas e metabólicas dos fungos anaeróbios do rúmen, vários estudos têm indicado que esses microrganismos desenvolvem importante papel na digestão e no ecossistema do trato digestório de ruminantes (Kamra, 2005). Esses fungos podem constituir até $8 \%$ da biomassa microbiana do rúmen nos animais que recebem dietas ricas em fibras e estão envolvidos na degradação da parede celular lignificada (Akin, 1987). A maior população fúngica no rúmen é observada em animais adultos e que ingerem maior proporção de fibras vegetais (Grenet et al., 1989). A principal espécie encontrada em bovinos é Neocallimastix variabilis, que é de ciclo monocêntrico, com zoósporos poliflagelados e filamentos com rizomicélio abundante. A espécie Anaeromyces elegans é também isolada no trato digestório desses animais, apresentando ciclo policêntrico, com zoósporos uniflagelados e filamentos com rizomicélio (Ho et al., 1993).

Poucos estudos têm avaliado a presença e a participação desses fungos no ambiente ruminal de animais criados em pastagens tropicais de baixo valor nutricional e frequentemente lignificadas, como as encontradas no semiárido brasileiro. A comparação da frequência desses fungos no ecossistema ruminal de bovinos e caprinos não tem sido respaldada na literatura científica. Por isso, o objetivo deste trabalho foi avaliar a presença de estruturas características de fungos anaeróbios no conteúdo ruminal de bovinos e caprinos de corte.

Recebido em 20 de novembro de 2009

Aceito em 10 de junho de 2010

*Autor para correspondência (corresponding author)

E-mail: duartevet@hotmail.com
Todos os animais amostrados eram provenientes da zona rural do município de Montes Claros, norte de Minas Gerais, e foram criados em pastagens naturais da região e em áreas de braquiária (Brachiaria decumbens e Brachiaria mutica). Essa região localiza-se a $16^{\circ} 51$ '38'de latitude e 445'00" de longitude, apresenta temperatura média anual de $24,2^{\circ} \mathrm{C}$, clima quente e seco, e um período de estiagem de abril a outubro que correspondeu ao período de coleta das amostras dos animais.

Foram coletados $15 \mathrm{~mL}$ do suco ruminal de 23 novilhos mestiços Nelore, com 30 a 40 meses de idade, diretamente do rúmen, após jejum de 12 a 18 horas, com o auxílio de pipetas estéreis. Nesses bovinos, a coleta foi realizada por incisão do rúmen, imediatamente, após o abate dos animais com a prévia concussão cerebral e sangria em um frigorífico com inspeção municipal. Os caprinos de corte avaliados eram machos mestiços Anglonubianos e com 18 a 22 meses de idade. A coleta foi realizada no momento da implantação cirúrgica de fístulas ruminais. Todos os procedimentos com os animais estiveram de acordo com o Comitê de Ética em Experimentação Animal da Universidade Federal de Minas Gerais protocolo $156 / 2005$.

As amostras foram transportadas em caixas isotérmicas a $4^{\circ} \mathrm{C}$ e armazenadas por, no máximo, uma hora em tubos de ensaio vedados e estéreis. Nos exames macroscópicos e físicoquímicos do líquido, foram avaliados cor, odor e 
viscosidade como recomendado por Dirksen (1993). O pH do líquido ruminal foi mensurado utilizando-se um potenciômetro digital imediatamente após a coleta.

Para exame direto dos fungos, foram recolhidos $2 \mathrm{~mL}$ do conteúdo ruminal, que foram transferidos para tubos de ensaio contendo $15 \mathrm{~mL}$ de solução de $\mathrm{KOH}$ a $10 \%$ para a clarificação. As amostras foram incubadas durante uma hora a $90^{\circ} \mathrm{C}$. O sobrenadante foi removido e os resíduos neutralizados com $10 \mathrm{~mL}$ de uma solução $0,02 \mathrm{~N}$ de HCL, durante um a dois minutos. Após desprezar a solução ácida, os resíduos foram transferidos para outros tubos contendo $15 \mathrm{~mL}$ de uma solução $0,05 \%$ de azul de metileno e lactoglicerol. O conteúdo foi analisado em um microscópio estereoscópio. As partículas que demonstraram a presença de esporângios, hifas e rizoides de fungos foram transferidas e montadas em lâminas com azul de metileno e examinadas sob a luz da microscopia óptica com aumento de 400 a 1000 vezes (Chaudhry, 2000).

O delineamento utilizado foi inteiramente ao acaso. Para comparar as médias de $\mathrm{pH}$ das espécies estudadas, utilizou-se o teste $\mathrm{t}$, e as taxas de detecção dos fungos foram analisadas pelo teste do qui-quadrado. Essas análises foram processadas no programa SAEG, considerando diferenças significativas aquelas com valores de $\mathrm{P}<0,05$.

As amostras do líquido ruminal apresentaram-se verdes, levemente espessas e aromáticas. Segundo Dirksen (1993), o suco ruminal com essas características apresentaria uma microbiota levemente ativa. Quanto ao $\mathrm{pH}$, não houve diferença significativa entre as espécies, variando de 6,2 a 7,7 nos caprinos e de 7,2 a 7,93, nos bovinos. As médias de $\mathrm{pH}$ para as diferentes espécies avaliadas estão dentro ou próximas dos valores normais, segundo Dirksen (1993). O valor do $\mathrm{pH}$ do conteúdo ruminal oscila entre 5,5 e 7,4, de acordo com a alimentação administrada e o intervalo de tempo da última alimentação. Neste estudo, o valor mais elevado de pH é justificado pelo tamponamento do conteúdo ruminal, pela salivação que foi favorecida pelo jejum e pelo tipo de alimentação, que se caracterizava principalmente por pastagens tropicais.

A técnica de detecção de fungos ruminais, descrita por Chaudhry (2000) e utilizada neste estudo, mostrou-se eficiente, prática e relativamente simples e pode ser utilizada como importante ferramenta para avaliar a presença desses microrganismos nos mais diferentes estudos de prevalência e ensaios de digestibilidade para ruminantes.

Estruturas fúngicas foram detectadas em 14 $(77,8 \%)$ dos 18 caprinos amostrados e em 17 $(73,9 \%)$ dos 23 novilhos. Esses dados demonstram alta taxa de detecção de estruturas compatíveis com as dos fungos anaeróbios do rúmen e que não houve diferença significativa para bovinos e caprinos. Na Tab. 1, encontra-se a proporção entre fungos monocêntricos e policêntricos para bovinos e caprinos. Em relação aos fungos monocêntricos (Fig. 1), como os do gênero Neocallimastix spp., não houve diferença significativa na taxa de detecção para os dois ruminantes avaliados $(\mathrm{P}=0,68)$. Fungos policêntricos, como os dos gêneros Orpinomyces e Anaeromyces spp., foram detectados em $50 \%$ das amostras provenientes de caprinos e em $26,1 \%$ das amostras provenientes de bovinos. Essa diferença também não foi significativa $(\mathrm{P}=0,11)$.

Tabela 1. Taxas de detecção de fungos monocêntricos e policêntricos do rúmen de caprinos e bovinos de corte criados em pastagens no norte do Estado de Minas Gerais, durante o período seco do ano

\begin{tabular}{|c|c|c|c|c|c|c|}
\hline \multirow{2}{*}{ Tipo de fungo } & \multicolumn{3}{|c|}{ Bovino } & \multicolumn{3}{|c|}{ Caprino } \\
\hline & Detectado & $\%$ & Total & Detectado & $\%$ & Total \\
\hline Monocêntricos & $13 \mathrm{~A}$ & 56,5 & 23 & $9 \mathrm{~A}$ & 50,0 & 18 \\
\hline Policêntricos & $6 \mathrm{~B}$ & 26,1 & 23 & $9 \mathrm{~A}$ & 50,0 & 18 \\
\hline
\end{tabular}

Valores com letras distintas na coluna diferem entre si pelo teste do qui-quadrado $(\mathrm{P}<0,05)$. Não houve diferença na taxa de detecção, segundo o tipo de fungo, entre bovinos e caprinos. 


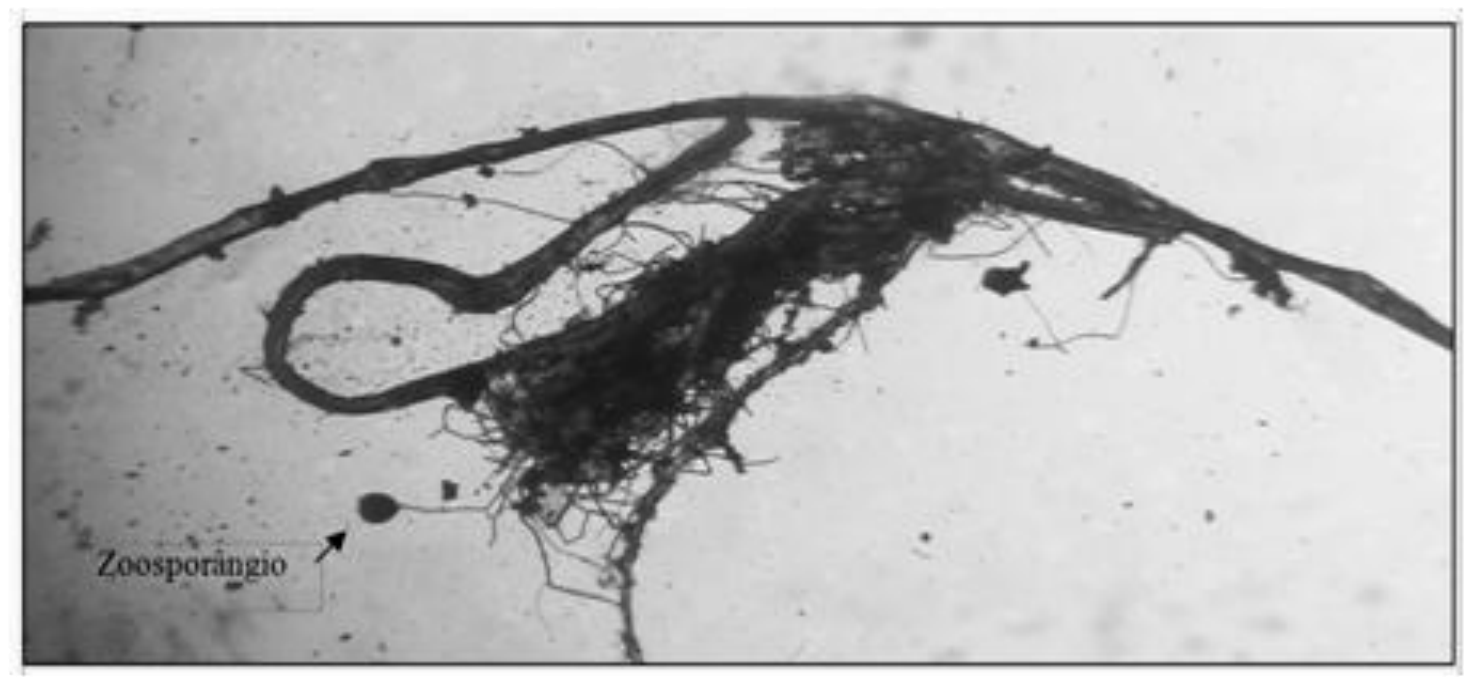

Figura 1. Estruturas de fungo monocêntrico aderidas às fibras vegetais observadas após exame direto com $\mathrm{KOH}$ de amostra de líquido ruminal de novilho Nelore criado em pastagens no norte de Minas Gerais (Objetiva de 40X).

Os resultados indicaram a presença concomitante de fungos monocêntricos e policêntricos para amostras de dois novilhos e de quatro caprinos, indicando a participação em conjunto desses dois grupos de fungos. Tem sido observada redução significativa da produção de gás in vitro e da degradação de alimentos fibrosos na ausência dos fungos ruminais. Dietas ricas em fibras estimulam o crescimento desses fungos em comparação com dietas contendo alta concentração de grãos (Kamra, 2005). A alta prevalência e a presença concomitante de fungos monocêntricos e policêntricos em caprinos e bovinos, observadas neste estudo, poderiam, então, ter sido favorecidas pela dieta rica em fibras disponível nas pastagens.

Ankur et al. (2006), em recente estudo que avaliou o potencial de fungos anaeróbios provenientes de caprinos e ovinos para a degradação de fibras vegetais, já tinham encontrado resultados semelhantes ao desta pesquisa, ao observarem a presença concomitante dos dois tipos de fungos. Foram identificadas amostras pertencentes aos gêneros Anaeromyces, Orpinomyces, Piromyces e Neocallimastix. Isolados deste último gênero, provenientes de caprinos, apresentaram atividade máxima de avicelalases e celulases, demonstrando maior atividade in vitro de degradação de matéria seca e fibra em detergente ácido (Ảnkur et al., 2006).
Nos bovinos, a frequência de fungos monocêntricos com características semelhantes às do gênero Neocallimastix foi significativamente maior que a de fungos policêntricos (Tab. 1; $\mathrm{P}=0,036)$. Uma das hipóteses poderia estar relacionada ao hábito mais seletivo de pastejo de caprinos em relação aos bovinos (Dirksen, 1993), favorecendo o crescimento de fungos monocêntricos $\mathrm{e}$ policêntricos nos caprinos em iguais proporções.

Hofmann (1973) relatou que caprinos, classificados como selecionadores intermediários, apresentam elevada taxa de passagem de alimento pelo trato digestivo, embora tenham menor capacidade de digerir a parede celular, e geralmente ingerem maior quantidade de alimentos, com valor nutricional mais elevado. Os bovinos, por sua vez, são classificados como pastejadores obrigatórios e menos seletivos, sendo aptos para digerirem qualquer tipo de alimento. No bovino, menos seletivo, a ingestão de alimentos mais fibrosos e lignificados poderia favorecer o grupo de fungos com maior atividade celulolítica. Segundo Fonty e Gouet (1994), os fungos monocêntricos do gênero Neocallimastix apresentam maior atividade, o que justifica, então, sua maior frequência no líquido ruminal dos bovinos, neste estudo. 
Ainda, neste trabalho foi demonstrada, pela primeira vez, a detecção de fungos ruminais em amostras provenientes de animais criados no semiárido do Estado de Minas Gerais, e foi registrada maior taxa de detecção de fungos monocêntricos nas amostras provenientes dos bovinos. Foi observada alta ocorrência para caprinos e bovinos criados em condições extensivas e em região tropical semiárida, indicando a importância desses microrganismos no ambiente ruminal desses animais.

Palavras-chave: caprino de corte, bovino de corte, fungo anaeróbico, ecossistema ruminal, semiárido

\begin{abstract}
The presence of anaerobic fungi structures was evaluated in ruminal juice of beef goats and beef cattle raised in the North of Minas Gerais, Brazil. The strains were collected from 18 Anglo-Nubian crossbred male goats and 23 Nellore crossbred steers during the dry period of the year. Physical-chemical characteristics of the juice were evaluated and direct examination with $\mathrm{KOH}$ digestion was performed for anaerobic fungi detection. Structures of these fungi were detected in samples of 14 (77.8\%) goats and 17 (73.9\%) steers. The monocentric fungi frequency (56.5\%) was significantly higher in cattle than polycentric fungi frequency (26.1\%). This study is the first report of anaerobic ruminal fungi in these ruminants in Brazil and showed high prevalence of theses microorganisms in the ruminal ecosystem of both animals.
\end{abstract}

Keywords: beef goat, beef cattle, ecosystem, anaerobic fungi, semi-arid

\section{AGRADECIMENTOS}

Este trabalho teve apoio do Conselho Nacional de Desenvolvimento Científico e Tecnológico (CNPq), da Fundação de Amparo à Pesquisa do Estado de Minas Gerais (FAPEMIG) e da PróReitoria de Pesquisa da Universidade Federal de Minas Gerais.

\section{REFERÊNCIAS BIBLIOGRÁFICAS}

ANKUR, T.; ANIL, K.P.; GUNJAN, G. et al. In vitro degradation of wheat straw by anaerobic fungi from small ruminants. Arch. Anim. Nutr., v.60, p.412-417, 2006.

AKIN, D.E. Association of rumen fungi with various forage grasses. Anim. Feed Sci. Technol., v.16, p. 273-285, 1987.

CHAUDHRY, A.S. Microscopic studies of structure and ruminal fungal colonization in sheep of wheat straw treated with different alkalis. Anaerobe, v.6, p.155-161, 2000.

DIRKSEN, G. Sistema digestivo. In: DIRKSEN, G.; GRÜNDER, H. D.; STÖBER, M. (Eds). Rosenberger: Exame clínico dos bovinos. Rio de Janeiro: Guanabara-Koogan, 1993. p.167-169.
FONTY, G.; GOUET, P.H. Plant cell wall degradation of anaerobic fungi. In: PRINS, R.A.; STEWART, C.S. (Eds). Micro-organisms in ruminant nutrition. Nottingham: Nottingham University, 1994. p.97-112.

GRENET, E.; JAMONT, J.; FONTY, G. et al. Kinetics study of the degradation of wheat straw and maize stem by pure cultures of anaerobic fungi observed by scanning eletron microscopy. Asian-Aust. J. Anim. Sci., v.2, p.456-457, 1989.

HO, Y.W.; BARR, D.J.S.; ABBULAH, N. et al. Anaeromyces, an earlier name for Ruminomyces. Mycotaxon, v. 47, p.283-293, 1993.

HOFMANN, R.R. The ruminant stomach: Stomach structure and feeding habits of east African game ruminants. Nairobi: East African Literature Bureau, 1973. 354p.

KAMRA, D.N. Rumen microbial ecosystem. Curr. Sci., v.89, p.125-135, 2005. 